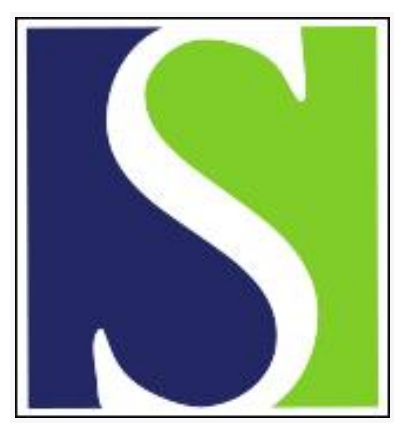

Scand J Work Environ Health 1995;21(2):81-83

https://doi.org/10.5271/sjweh.14

Issue date: Apr 1995

Exposure to pollutants through consumption of contaminated fish

by Skerfving $\mathrm{S}$

This article in PubMed: www.ncbi.nlm.nih.gov/pubmed/7618062

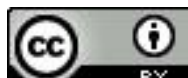




\section{Exposure to pollutants through consumption of contaminated fish}

Fish have a tendency to accumulate water pollutants. This tendency can lead to health consequences for fish consumers. In the 1960s, hundreds - possibly thousands - of fishermen and their wives in the Minamata and Niigata areas in Japan were poisoned from contaminated fish (1). Inorganic mercury had been discharged into the sea, where it had been transformed into methylmercury, which accumulated in fish and shellfish. In addition to severe neurotoxic effects in adults, there was also prenatal brain damage in fetuses. Later, it was discovered that the methylmercury contamination of the fish was not an exceptional incident, but rather a phenomenon occurring in many mercury-contaminated lakes, rivers, and coastal areas. Moreover, it was found that the fish species at the top of the marine food chains may contain high methylmercury levels even far out at sea.

The Baltic Sea is a marine environment that was heavily polluted with mercury. Thus subjects with high intake of fish from some coastal areas have a considerable methylmercury load. But it became evident already in the 1960s that the contamination of Baltic fish was more complex. Hence fat fish such as salmon and herring contained high levels of DDT (dichlorodiphenyltrichloroethane) and its metabolites. Furthermore, subjects with a high intake of such fish had a manifold increase in the blood levels of these agents (2). As DDT is efficiently excreted into human milk, there was great concern about the exposure to breast-fed infants.

But methylmercury and DDT was only the beginning. Thus the Swedish chemist Sören Jensen, while studying the bioaccumulation of DDT, found high levels of what was later identified as polychlorinated biphenyls (PCB), which had been widely used, for example, in electrical equipment (3). As in the cases with other contaminants, it soon turned out that other areas in the world were also heavily contaminated, for example, the Great Lakes. The toxic potency of these compounds to humans was revealed when they caused mass poisoning due to the contamination of rice oil in 1968 in Japan and in 1979 in Taiwan (4).

Soon, the analytical chemists revealed new unpleasant facts. The fat fish from the Baltic Sea also harbored many compounds belonging to the chemical families polychlorinated dibenzofurans (PCDF) and dibenzo-para-dioxins (PCDD). In the case of the most prevalent of the PCDF - 2,3,4,7,8-pentachlorodibenzofuran (PeCDF) - the main source was probably incineration, for others it was pollution from the paper and pulp industry, which used chlorine for bleaching. For the other congeners, many different sources contributed.

PCDD have a bad reputation because they are distributed to the fat tissue, have a slow elimination rate, and the most toxic congener - 2,3,7,8-tetrachlorodibenzo-para-dioxin (TCDD) - is the most toxic compound synthesized by mankind (5). One impressive trait of TCDD is its extremely varying toxicity in different species. This variation makes the toxicologic evaluation as to human risks very uncertain. However, TCDD has caused several cases of human poisoning. In addition, there was widespread exposure of the armed forces and general population in connection with herbicide use in the Vietnam war, and a major outbreak among the general population at the industrial accident in 1976 in Seveso, Italy. Furthermore, PCDD/PCDF are excreted in breast milk.

Other congeners of the PCDD/PCDF group also have similar effects, but with extremely varying potency. It is supposed that the effect is mediated through binding to the cytoplasmic Ah receptor. Thus there was a need to establish a summary index of all similar congeners. Hence the toxic equivalency factor concept was established on the basis of experimental data. The combined content of PCDD/PCDF, for example, in foods, can thus be expressed as TCDD equivalents (TEQ). PCB contain congeners - the coplanar non- and monoortho- PCB, which have TCDD-like effects. Thus TEQ from PCB may be added to those from PCDD/PCDF, although this is far from all of the truth about PCB toxicity, because some congeners have other effects, which are probably mediated through other mechanisms.

It turned out that subjects who consumed high amounts of fish from the Baltic Sea had increased levels of PCDF/PCDD in their blood (6). Furthermore, they had increased concentrations of several PCB congeners, 
including coplanar ones $(7,8)$. In fact, as to the total TEQ in blood, the PCB made the greatest contribution. Moreover, it was obvious that fish was a major source of these compounds in the Swedish population, although subjects who never ate fish also had a load.

This issue contains a paper verifying the importance of fat fish from the Baltic Sea as a main source of human exposure to PCDD/PCDF and PCB (9). Among Swedish fishermen, who have a high intake of fish, those fishing in the Baltic Sea had much higher blood levels of these compounds than those fishing in the North Sea (including Kattegatt and Skagerrak), in which the fish are less contaminated.

Of course, a main issue is whether this dietary exposure is of any toxicologic relevance. It is important to stress that we do not know. PCDD are well known to cause cancer, reproductive effects, and immunosuppression in experimental studies. PCB have similar effects. Thus these effects are the ones that should primarily be considered. Hence it is interesting that a cohort study of fishermen from the Baltic and the North Sea, which also appears in this issue (10), indicates some differences in cancer morbidity. Thus the Baltic fishermen had an increased incidence of stomach and skin cancer and increased mortality from multiple myeloma.

Obviously, these data, though interesting, do not allow conclusions to be drawn about a causal relationship between dietary exposure to contaminants in fish and tumor induction. The skin cancer may well be due to exposure to ultraviolet light. Moreover, the other findings may be due to multiple inference. In addition, there is a possibility of confounding. Hence the contaminants of the fish consumed are probably not the only difference between the two cohorts of fishermen. Thus firm conclusions must await further studies. However, it is interesting to note that myelomas have been reported in the general population exposed at Seveso (11). Furthermore, Baltic fishermen's wives seem to have an increased risk of breast cancer (12), a tumor which has also been associated with PCB exposure in other investigations.

Moreover, other studies may indicate additional adverse health effects. Thus there are some indications of an association between the intake of fat fish from the Baltic Sea and immunologic effects $(13,14)$. Moreover, the wives of Baltic fishermen (who also have a high intake of fish), more often give birth to infants with low birthweight than do the wives of North Sea fishermen (15). This finding is particularly interesting since decreased birthweight was also reported for women who eat fish from Lake Michigan, which is contaminated with PCB, presumably in combination with many other agents (16). Furthermore, the Lake Michigan children possibly showed some effects on mental development (4).

The PCB exposure (other pollutants were not assessed) of the Lake Michigan women corresponded to an intake of only $54 \mu \mathrm{g} \cdot \mathrm{d}^{-1}$ (though the estimate is very rough). If this is applied to the consumption of fat fish from the Baltic Sea, it would correspond to only a few meals per week. Furthermore, because of the slow elimination of PCDD/PCDF and some PCB, any such consumption before a pregnancy would influence the exposure of the fetus and the breast-fed infant. Thus the interpretation of the shaky toxicologic and epidemiologic information has great practical implications.

Fish is an important food. It is a major source of, for example, selenium $(17,18)$ and $n-3$ polyunsaturated fatty acids (19). The Baltic fishermen had low mortality from coronary heart disease (10), and this low mortality may be associated with the positive aspects of fish intake. It is tragic that a food as important as fish has been affected by pollution to a such a degree that authorities even consider recommendations restricting its intake.

One light in the darkness is the fact that the restrictions, enforced in Sweden and other countries for the use of DDT and PCB, seem to have been effective. Thus during the last few decades, the concentrations of DDT and its metabolite DDE have decreased dramatically in the blood of Baltic fishermen (8). Such a decrease has also occurred for PCB in Swedish breast milk (20). Furthermore, it seems that the levels of some PCDD/PCDF congeners have also decreased in breast milk, possibly as a result of the reduction of chlorine bleaching in the paper and pulp industry, which partly occurred already before the awareness of the problem.

On the other hand, there are probably many other pollutants yet to be detected, once the analytical techniques are available. There is, for example, toxaphene contamination of the fish. Furthermore, recently, a new group of pollutants was identified in fish, as well as in the blood of Baltic fishermen - polychlorinated naphthalenes (21). Hence it is important that skilled analytical chemists and environmental toxicologists continue to identify and assess the toxicity of pollutants in fish. 


\section{References}

1. World Health Organization (WHO). Methylmercury. Geneva: WHO, 1990. Environmental health criteria 101.

2. Kolmodin-Hedman B, Palmér L, Götell P, Skerfving S. Plasma levels of lindande $\mathrm{pp}$-DDE and $\mathrm{pp}^{\prime}$-DDT in occupationally exposed persons in Sweden. Work Environ Health 1973; 2:100-6.

3. Jensen S. Report on a new chemical hazard. New Sci 1966; 32:612.

4. Ahlborg UG, Hanberg A, Kenne K. Risk assessment of polychlorinated biphenyls (PCBs). Copenhagen: Nordic Council of Ministers, 1992. Nord, no 26.

5. Ahlborg UG, Håkansson $\mathrm{H}$, Waern F, Hanberg A. Nordic dioxin risk assessment [in Swedish]. Copenhagen: Nordic Council of Ministers, 1988. Nord, no 7.

6. Svensson BG, Nilsson A, Hansson M, Rappe C, Åkesson B, Skerfving $S$. Exposure to dioxins and dibenzofurans through the consumption of fish. N Engl J Med 1991;324:8 - 12.

7. Skerfving S, Svensson B-G, Asplund L, Hagmar L. Exposure to mixtures and congeners of polychlorinated biphenyls. Clin Chem 1994:40:1409-15.

8. Asplund L, Svensson BG, Nilsson A, Eriksson U, Jansson B, Jensen $\mathrm{S}$, et al. $\mathrm{PCB}, \mathrm{pp} \mathrm{p}^{\prime}-\mathrm{DDT}$ and DDE in human plasma related to fish consumption. Arch Environ Health. 1994:49: $477-86$.

9. Svensson B-G, Nilsson A, Jonsson E, Schïtz A, Åkesson B, Hagmar L. Fish consumption and exposure to persistent organochlorine compounds, mercury, selenium and methylamines among Swedish fishermen. Scand J Work Environ Health 1995;21:96-105.

10. Svensson B-G, Mikoczy Z, Strömberg U, Hagmar L. Mortality and cancer incidence among Swedish fishermen with a high dietary intake of persistent organochlorine compounds. Scand J Work Environ Health. 1995;21:106-15.

11. Bertazzi PA, Zochetti C, Peastori AC, Guercilena S, Sanarico M, Radice L. Ten-year mortality study of the population involved in the Seveso incident in 1976. Am J Epidemiol 1989; 129:1187-200.

12. Rylander L, Hagmar L, Strömberg U. Increased incidence of breast cancer among fishermen's wives with high consumption of PCB contaminated fish from the Baltic Sea [abstract, in
Swedish]. Hygiea 1994;103:114.

13. Svensson B-G, Hallberg T, Nilsson A, Schütz A, Hagmar L. Parameters of immunological competence in subjects with high consumption of fish contaminated with persistent organochlorine compounds. Int Arch Occup Environ Health 1994; $65: 351-8$.

14. Hagmar L, Hallberg T, Marcis L, Nilsson A, Schütz A. High consumption of fatty fish from the Baltic Sea is associated with changes in human lymphocyte subset levels. Toxicol Lett. In press.

15. Rylander L, Strömberg U, Hagmar L. Decreased birthweight of infants born to wives of Baltic Sea fishermen with a high dietary intake of fish contaminated with polychlorinated biphenyls. Scand J Work Environ Health. 1995;21:00-00.

16. Fine GG, Jacobson JL, Jacobson SW, Schwartz PM, Dowler JK. Prenatal exposure to polychlorinated biphenyls: effects on birth size and gestantional age. J Pediatr 1984;105:315-20.

17. Svensson B-G, Schütz A, Nilsson A, Åkesson I, Åkesson B, Skerfving S. Fish as a source of exposure to mercury and selenium. Sci Total Environ 1992;126:61-74.

18. Huang W, Åkesson B, Svensson B-G, Nilsson A, Burk RF, Skerfving $\mathrm{S}$. Selenoprotein $\mathrm{P}$ and glutathione peroxidase in plasma as indices of selenium status in relation to the intake of fish. Br J Nutr. In press.

19. Svensson B-G, Åkesson B, Nilsson A, Skerfving S. Fatty acid composition of serum phosphatidylcholine in healthy subjects consuming varying amounts of fish. Eur J Clin Nutr 1993;47: $132-40$.

20. Norén K, Lundén $\AA$. Trend studies of polychlorinated biphenyls, dibenzo-p-dioxins and dibenzofurans in human milk. Chemosphere 1991;23:895-901.

21. Asplund L, Svensson BG, Nilsson A, Eriksson U, Jansson B, Jensen $\mathrm{S}$, et al. Levels of polychlorinated naphtalenes (PCN) in human blood plasma with reference to fish intake. In: Asplund L. Development and application of methods for determination of polychlorinated organic pollutants in biota [thesis]. Stockholm: Institute of Applied Environmental Research, Laboratory of Analytical Environmental Chemistry, Stockholm University, 1994.

Staffan Skerfving, $M C$

Department of Occuparional and Environmental

Medicine

Institute of Laboratory Medicine

University Hospital

Lund, Sweden 